\title{
Prospects of Solar Energy in Oman: Case of Oil and Gas Industries
}

\author{
Kenneth E. Okedu**, Husam AL Nadabi*, Ahmed Aziz* \\ *Department of Electrical and Computer Engineering \\ National University of Science and Technology, Muscat, Sultanate of Oman \\ (Okedukenneth@nu.edu.om or kenokedu@yahoo.com, alnadabi-91@ hotmail.com, al-qaysi@live.com) \\ $\$$ Corresponding Author; Kenneth E. Okedu, Tel: +9689144 6270, \\ Okedukenneth@nu.edu.om or kenokedu@yahoo.com
}

Received: 02.07.2019 Accepted:18.08.2019

\begin{abstract}
The recent fall in oil prices made oil and gas companies to rethink their production strategies and optimize their expenses, while at same time, optimally extract oil in a cost-effective way. A combination of rising oil demand and declining supply from the conventional sources is drawing global attention to the vast heavy-oil resources. Heavy oil has high viscosity and is commonly developed with steam-based processes which, in most cases, burn fossil fuel to generate the required steam. However, tightening constraints on fuel, water, and the environment are some of the factors currently fuelling the interests to enhance the traditional steaming operations. Generating steam using solar energy has overcome the challenges of steam been produced from burning of natural gas. The most common challenge is that steam production using natural gas burnt facilities are expensive and the cost of natural gas required to generate steam is considerably high. The use of renewable energy system is the best alternative to achieve reduction of the high cost of energy supply and carbon emission. Due to the heavy nature of the oil explored from Oman, the cost of drilling is quite high and also involves a lot of fossil energy to heat up the heavy oil to reduce its viscosity, reduce the pressure of the system, ease the flow and make it light before drilling. A new technology know as the Enhanced Oil Recovery is been proposed using solar energy instead of the conventional fossil energy, in order to save cost and the same time, make the environment eco-friendly. This paper presents prospects of solar farm steam generator-based technology, in the southern part of Oman, where the requirement of steam for oil exploration is high. The Amal and Amin oil fields were used as case studies. The solar steam generator model was analyzed considering some of the technical designs in the enhanced oil recovery process, compared to traditional schemes used for oil extraction. With installation of solar based steam generators, gas consumption for steam generation and environmental pollution would be reduced substantially. Also, some of the benefits and challenges of the concentrating solar power steam technology employed were highlighted. Moreover, the opportunities the solar farm could offer to the Sultanate in general were discussed.
\end{abstract}

Keywords Solar energy, steam generation, enhancement oil recovery, oil wells, viscosity, renewable energy.

\section{Introduction}

\section{Motivation}

With the present global warming issues, and the rising demand of energy, the use of renewable energy is on the rise. It is obvious that the peak electricity demand in Oman is increasing from $2773 \mathrm{MW}$ in 2007 to an expected 10000 MW in 2019, due to population rise and industrial revolution. Electricity generation and electricity shortages are bound to occur as the years go by based on the current trend. The government of the Sultanate of Oman accounts for $29.16 \%$ of total gas production, while the rest is deployed in oilproduction and for export [1]. About $92 \%$ of the natural gas is used internally for electricity generation [2]. If care is not taken, the continuous building of gas fired power stations, would led a scenario where electricity generation in Oman will be based on importation rather exportation of natural gas. This is because all the power stations are nonrenewable fossil technology. Consequently, it is paramount to focus on alternative sources of energy, based on the following criteria: been renewable, available locally, and pollution free. Fortunately, Oman happen to have a great potential in the Middle East regional utilization of renewable energy sources, especially solar energy. In light of the above, the application of solar energy in the oil and gas industries is not left out, especially since Oman oil is heavy compared to other countries. Due to the heavy nature of the oil explored from Oman, the cost of drilling is quite high and also involves a lot of fossil energy to heat up the heavy oil to make it light 
before drilling. Therefore, it is imperative to propose a technological model based on solar steam heating, known as Enhanced Oil Recovery, to replace the traditional fossil energy based steam generation scheme, in order to save cost and the same time, make the environment eco-friendly.

\section{Literature Review}

Recently, the application of renewable energy in power production is on the rise in the world [3-5]. Amongst the various renewable energy sources, solar and wind energy are playing a vital role due to their vast technological growth and availability. Solar energy tends to be more useful in the Gulf countries because of the high sun intensity in the region. The use of solar energy is imperative for the supply of electric power in the Sultanate of Oman. Based on the huge land availability and abundant solar energy resources, Oman has an excellent potential for solar energy development and deployment [6]. It is no doubt that solar energy is a viable option in Oman to take care of the growing need for energy and economic diversification. In 2010, the government of Oman declared Middle East and North Africa (MENA) wind power project, as one of the two pilot projects to be implemented immediately, which is located in Masirah Island. Also, Oman government has initiated solar project which will be in operation by 2019 , with capacity up to 200 MW, located near Adam and Manah.

With a total dependence on fossil fuels and increasing population, in conjunction to the fast and rapid industrialization in the country, hydrocarbon reserves pose a challenge on the economic growth. The strategic geographical location of the Sultanate of Oman makes it viable to harness renewable energy technologies such as solar energy for effective development of its economy. Apart from mitigating the over dependence on fossil fuels, it also encourages the creation of cleaner and sustainable environment, employment and the economy diversification. In Oman, the main types of renewable energies in use are wind and solar.

In the literature, a lot of report already exist in the application of solar energy system in the following areas [715]: solar water heating, solar heating of buildings, solar distillation, solar pumping, solar drying of agricultural and animal products, solar furnaces, solar cooking, solar electric power generation, solar thermal power production and solar green houses. In several countries, solar energy has been applied in off grid standalone systems to power electrical utilities [16, 17] including industries.

The use of solar energy for advance applications in the agricultural sector was reported in [18], where solar environmental control system of greenhouses (cooling, heating and lightning) as well as PV water pumping for irrigation purpose were implemented. The application of solar energy in water treatment processes was reported in [19], where solar energy is used to drive water treatment processes as a potential sustainable solution to the world's water scarcity issue. In [20], solar energy was employed in automotive applications and it was reported that solar energy could be used in electric and hybrid cars in order to reduce environmental pollution and high cost of fossil fuels.

The growing energy demand makes oil to play a vital role as one of the leading primary energy sources [21]. Thus, the easiest strategy to extract it from the earth crust putting into consideration a cost-effective way is very paramount. The combined rise in oil demand and decline in supply from the traditional energy sources is pushing global attention to the vast heavy-crude oil resources. Basically, this topology is based on developing steam-based processes that require the effective combustion of fossil fuel in order to generate the required amount of steam. However, due to the limit on fuel, water, and the environmental factors, attention is moving from the enhancements of the traditional steaming operations [22] and the use of renewable energy system as the best alternative. With the use of renewable or alternative energy sources, the high energy supply cost of traditional energy systems could be avoided and reduction in carbon emissions would be achieved [23].

In Oman, the total area of land is $212,460 \mathrm{~km}^{2}$ with a coastline that sums up to $2092 \mathrm{~km}^{2}$ and it is located in the Middle East, on the eastern edge of the Arabian Peninsula. The Sultanate has a latitude and longitude of $(2100 \mathrm{~N}, 57$ $00 \mathrm{E})$. The climate is generally very hot, with temperatures reaching $48{ }^{\circ} \mathrm{C}$ in the hot season, from May to August. Also, there are hardly rainfalls in Oman, thus, making the climate of Oman dry and extremely hot, although the coastal areas are humid most times [24-27]. As at 2018, the total population of Oman is about 4.5 million people, with Omanis accounting for about 2.5 million people. There are nine districts of administartion in the Sultanate: Muscat, Musandam, Dhofar, Al Buraimi, Al Batinah, Adh Dhahirah,Ad Dakhliyah, Ash Sharqiyah, and Al Wusta. Based on the literature, the following sectors share in the Gross Domestic Product GDP reached (in million of Omani Rial OR): 7317.2 oil and gas, 258.6 agriculture and fishing, 3325.3 industrial activities, and 7519.0 service activities $(0.387$ OR $\approx 1$ US\$) [2, 24].

For many decades, Oman industrial development was based on small scale manufacturing. However, with early $90 \mathrm{~s}$ discovery of large deposits of non-associated natural gas, the government focus drifted to large capital-intensive gas-based projects. Consequently, the following major industrial companies were established; Raysut, Sohar, Nizwa, Sur and Buraimi industrial estates.

Furthermore, the discovery of natural gas in the late $80 \mathrm{~s}$ and early 90s, opened avenue for development of gas-based industry in the Sultanate as part of its diversification plans. Sohar, is said to host industrial port with specified containerhandling facilities, and gas is supplied by pipeline from central Omani fields to this location.

The electricity companies former structures are constructed from the following government owned companies: Electricity Holding, Oman Power and Water Procurement, Oman Electricity Transmission, Wadi Al Jizzi Power, Al Ghubrah Power and Desalination, Mazoon Electricity, Majan Electricity, Muscat Electricity Distribution, and Rural Areas Electricity Companies [2, 6]. The key market sectors have three separate and distinct 
markets: Main Interconnected System (MIS), the Rural Systems (RAECO) and the Salalah Power System. The estimated forecast of the MIS Electricity Demand peak will increase from $2773 \mathrm{MW}$ in 2007 to an expected $10000 \mathrm{MW}$ in 2019 [1, 2, 28]. Apparently, the current power generation in the Sultanate is based on fossil fuel, which is not renewable.

According to reference [29], the production of oil is separated into three phases: primary, secondary, and tertiary. Primary recovery involves extracting hydrocarbons that naturally rise to the surface, while during the second phase water and gas are injected into the well to push oil to the surface. In [30], it was reported that, when the production oil well is established, only $20-40 \%$ of the potential oil can be extracted through the first two phases.

The implementation of the Enhanced Oil Recovery (EOR) provides an opportunity to extract up to $30 \%$ of the original oil reserve in the well. Furthermore, it has been estimated that $2.0 \times 1012$ barrels of conventional oil and 5.0 $\times 1012$ barrels of heavy oil remain in reservoirs worldwide, after the exhaustion of the applications of conventional recovery methods [31]. The application of EOR helps extract these reserves and guarantee a continue supply of oil in the future. Concentrating solar power plants [32] can be used to generate high temperature heat that drives steam turbines by the use of mirrors for systems that were traditionally powered from conventional fossil fuel. Some of these systems operate during cloudy weather and night-time by incorporating also heat storage. The main systems that are operational today in various countries are the Parabolic Trough Collector (PTC) system and the central receiver or power tower system.

\section{Contributions}

This work presents the use of solar energy in the current state-of-the-art application considering oil and gas technologies in the Sultanate of Oman, with focus on solar steam generation. Renewable source of energy like Solar Photo Voltaic (PV) could be used to generate steams for power and also get injected into oil wells to reduce the high viscosity of oil, in order to aid its extraction and ease its flow, instead of using fossil fuel powered plant, which is quite expensive. This work proposes the use of Solar Photovoltaic Energy Steam Generator in the oil and gas sector, by using the topology of solar farm to produce steam for the EOR process in oil wells. The traditional scheme used by the oil and gas companies is to inject steam in the process of the extraction of oil in the oil wells, in order to reduce the pressure of the system. However, this conventional method is quite expensive considering the amount of fossil fuel that is to be consumed and the release of pollutants into the atmosphere.

\section{Organization of the paper}

The paper is organized as follows: section 1 is the Introduction, section 2 give a brief overview of the oil and gas sectors in Oman. Section 3 deals with the overview of electricity sector and solar energy penetration in Oman, while section 4 presents traditional steam generation schemes. Section 5 is about the background of the Amal oil fields used in this study, while sections 6 and 7 address the proposed enhanced oil recovery technique applied in Oman oil and gas industries and some of the opportunities offered by the Miraah solar farm project, respectively. Finally, the conclusion and recommendations of the work are given in section 8 .

\section{Overview of Oman Oil and Gas Sectors}

The oil and gas sectors are the most efficient and profitable sectors for countries that rely solely on fossil fuel natural resources. The demand for energy in the Sultanate of Oman is increasing rapidly because of population and economic growth, coupled with industrial development. Consequently, the power infrastructures and hydrocarbon reserves are under pressure. In the past, Oman has experienced severe power disruptions due to constrained oil and gas resources. Recently, the Sultanate of Oman began to examine the potential use of renewable natural resources, in a bid to diversifying the energy mix. The oil reserves in Oman are located in north and central onshore areas and are composed of many separate clusters of smaller fields. The total Omani oil reserves are 5.5 billion barrels. Figure 1, illustrates the comparison of oil reserves of Oman to other Gulf countries [33].

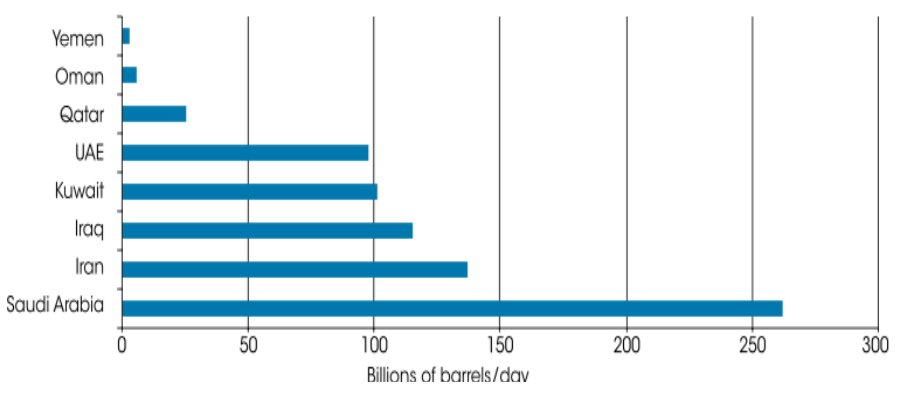

Figure 1: Proven oil reserve of Oman in comparison to other Middle East countries

The oil in Oman is highly viscous and only a part of it is recoverable using old traditional production methods, thus, resulting in high production cost. Oman succeeded to reversing decline crude oil production by using sophisticated methods of EOR. The projection in 2007 onwards, shows that the Oman crude oil production has increased by $30 \%$, reaching value estimated over $920000 \mathrm{bbl} / \mathrm{d}$ [34]. By employing EOR via injection method of steam, more crude oil from reserves could be extract. Currently, 20\% of domestic gas are used for EOR in the Sultanate. Although, solar energy resources in Oman offer a practical potential for replacing an important part of this gas, which would also save a lot of wealth.

Natural gas in Oman has substantial reserves, which makes the Sultanate a leading regional exporter of Liquefied Natural Gas (LNG). Verified gas reserves amount to 30 trillion cubic feet (Tcf) as of January 1, 2011. Figure 2, illustrates the top Middle East natural gas exporters in recent years. From 2011 till date, an estimated total production of natural gas in Oman is around 937 billion cubic feet (Bcf) [35]. The consumption of natural gas in Oman rose $200 \%$ between 2000 and 2012 [36], and this value has increased in recent times. Oman natural gas is mainly used for electricity 
generation, water desalination and EOR. Recently, the consumption of natural gas has tripled according to reference [37], whereas, total exports and EOR gas usage has declined slightly. From the end of 2005 till date, there have been continued increases in gas use for electricity generation and industrial usage.

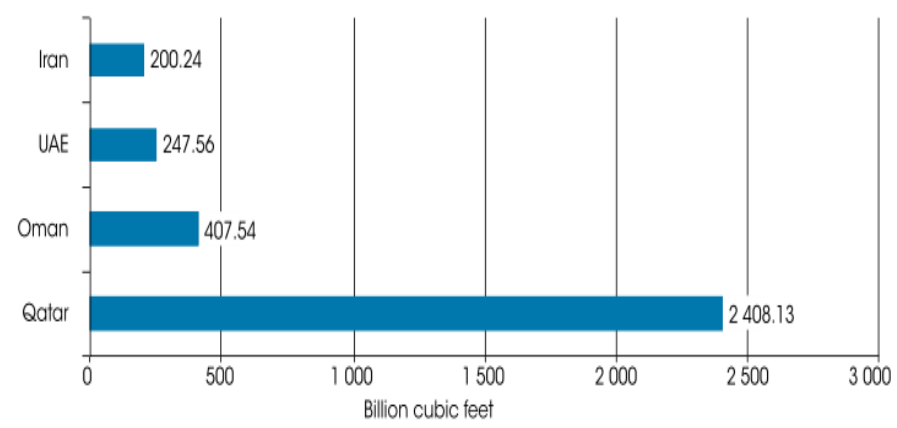

Figure 2: Top Middle East natural gas exporters

\section{Overview of electricity sector and solar energy penetration in Oman}

Oman electricity is mainly based on natural gas; $97.5 \%$ and the remaining $2.5 \%$ by diesel. The economical, industrial and population growth, with low electricity prices put a strain on the power infrastructure of the country. The weather in Oman is very hot and unpleasant in summer seasons, as a result, drastic peak loads are experienced leading to incessant power failure. The peak power demand in the summer is normally registered in June and July with temperatures going as high as 50 degrees Celsius. In 2013, 4.717 GigaWatt (GW) peak power demand was reached, compared to 2004 with a value of 2.495 GigaWatt (GW) [38], and recently this value has increased tremendously. Based on the literature, there was $89 \%$ increase of the power demand in Oman during summer seasons. Thus, putting the country on pressure to getting sufficient production capacity to the grid in proportion to the growth in demand.

The location of Oman makes it a huge advantage in terms of getting highest solar energy density in the world. Consequently, solar radiation value and daily sunshine duration have been calculated for different locations in the Sultanate. Marmul, Fahud, Sohar and Qairoon Hairiti are considered to have the highest solar radiation in Oman. Figure 3, illustrate the highest and lowest insolation areas in the country where, the desert areas have the highest insolation compared to the coastal areas in the southern part of Oman that has the lowest insolation [39]. In summary, given the huge unused land available with high solar resources, Oman has clearly excellent potential for scale solar exploitation [40].

\section{Traditional Steam Generation}

\subsection{Boiler Fuel}

Base option considered for Amal steam project is to use natural gas with options for Cogen with Heat Recovery System Generator (HRSG). The crude or liquid burn option for the Once Trough Steam Generator (OTSG) has also been extensively investigated. It is well recognized that once a decision is made that a liquid fuel is to be used, then the least expensive source is either a refinery bottoms product which is discounted relative to crude oil prices or in-field crude oil. Refined products such as gasoline or diesel are not cost -

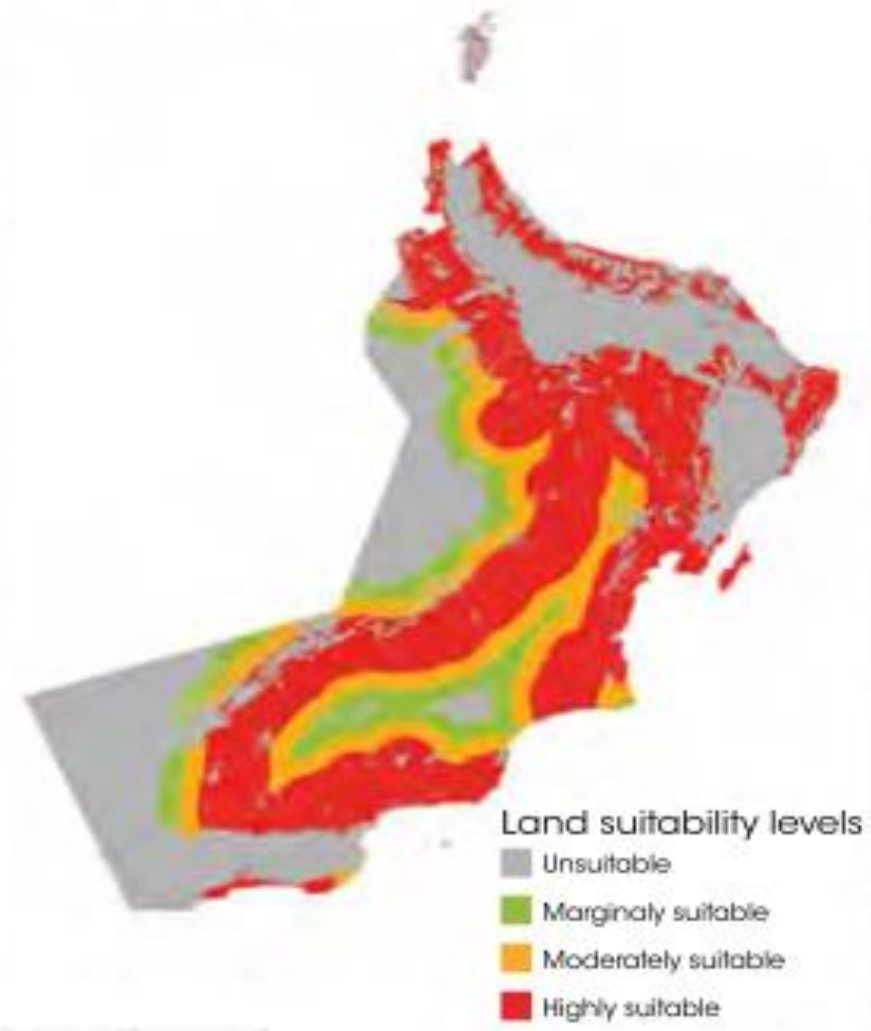

Figure 3: Spatial distribution of land with suitable levels for solar PV energy project

-effective. Solid fuels such as coal are only applicable in large power plant type operations.

First and foremost, crude oil generally contains sulphur which when burned, creates oxides of sulphur. Secondly, particulates will be created in the burner operation. Thirdly, control of nitrogen oxides is more difficult when crude is burnt. Fourthly, crude oil generally needs to be preheated to around $300{ }^{\circ} \mathrm{F}$ to get the viscosity low enough to facilitate good atomization in the burner nozzles.

Crude oil fired steam generators (50 MMbtu/hr sized units) have however been field proven in operations for years along with the necessary emission control technology required to meet air quality standards for the oxides of nitrogen (NOx) and oxides of sulphur (SOx). OTSG vendors have advised that they would limit the size of oil fired OTSG units to $50 \mathrm{MMBTU} / \mathrm{hr}$ units. Larger OTSG units are being used elsewhere where natural gas is the fuel source, but the 50 MMBTU units are the only field proven technology for oil fired. Vendors relate the issues of flame stability and burner modifications which were solved to prevent radiant tube flame impingement, convection section soot fouling and NOx control. They believe attempting to utilize the larger and slightly more cost effective steam generators would 
require significant research to become proven for remote field application.

Crude firing OTSG units results in two air emissions issues which must be managed. One is the amount of oxides of nitrogen created in the combustion zone. A second issue is the amount of sulphur dioxide emitted. The potential environmental aspects of oil fired generators typically are up to $5 \%$ less efficient than their equivalent gas fired ones, as the convection section fin tubes will typically foul with soot and other ash rendering reduced thermal efficiency. This leads to the fins being built less tightly for ease of cleaning that in turn reduces the overall efficiency.

\subsection{Steam Injection}

Steam injection is considered as the most commonly used EOR method today as the recovery of this method is noticeable. By injecting steam into reservoir, the viscosity of oil decreases which makes it easy to extract. The viscosity of oil is determined by the API (American Petroleum Institute), so if the API of the oil is high, thus the oil is heavy and vice versa. Steam injection is basically a process of heating the reservoir to reduce the viscosity of oil and make it more light, so as the temperature increases, viscosity of oil decreases. When the viscosity of oil is decreased, it improves the mobility ratio and this will enhance sweep efficiency.

\subsection{Types of steam Injection}

There are three types of steam injection methods, these are cyclic steam injection, continuous steam injection and Steam Assisted Gravity Drainage (SAGD).

\section{Cyclic steam injection}

Is a single vertical or horizontal well that injects a predetermined steam volume and then give it time to distribute the injected heat followed by a production period. The response of this method depends on the type of reservoir. Also this method failed in horizontal reservoir as the energy is depleted quickly which limits the number of cycles.

\section{Continuous steam injection}

Also called steam flooding, in this process the steam is injected near the base of the heavy oil reservoir through an injection well. The injected steam vapor will raise towards the top of the reservoir and as the injected steam comes into contact with oil, it transfers heat into the cold heavy oil, reducing the viscosity of the oil and make it more mobile.

\section{Steam Assisted Gravity Drainage (SAGD)}

In this process two parallel pipes are drilled deep down in the earth and then go horizontal. The top one is called the steam injecting well and the bottom one is called the producer well. Then high pressure steam is injected down into the reservoir and over time the oil become less viscos which means it flows more freely, so it drops down into the bottom well where it pumps up to the top.

\section{Technical Background and History of the Amal Oil Fields}

The locations of this study are the Amal West and East oil Fields in the Eastern Flank of the South Oman Salt Basin, $30-35 \mathrm{~km}$ South South West of the Nimir [41]. The Amal West field is located on the Eastern Flank of South Oman Salt basin 30km South South West of the Nimir fields. The field at Haima level is a classic high relief fault bounded, anticline approximately $4 \times 2 \mathrm{kms}$ oriented North-South. The field was discovered in 1972 by Amal-1, drilled on the crest of a closure mapped at base Nahr Umr. Production started in 1984 through temporary facilities and was brought fully on stream in 1987 after commission of the Amal Gathering [42, 43]. The field consist of Haima pod comprising four formations; Karim, Haradh, Amin and Mahwis. The latter three are oil bearing.

Additionally, the fields produce from Al Khlata P5 and the Middle and Lower Gharif reservoirs. Daily net production is $1900 \mathrm{~m}^{3}$ with water production at $19200 \mathrm{~m}^{3}$. The maximum height of the oil column is c. $200 \mathrm{~m}$, found on the central part of the Haima, pod, sealed by a combination of Ak Khata diamictities and the Nahr Umr shale. Initial pressure was recorded at $12100 \mathrm{kPa}$ at reservoir datum. Present pressure is c. $7500 \mathrm{kPa}$ after more than 20 years production.

The Amal East field is located $2 \mathrm{~km}$ East of Amal West. Like the Amal West, the field consist of a Haima pod. It is turtle back anticline structure with steeply dipping flanks and is about $1.5 \times 1.5 \mathrm{~km}$ in size. Only the Haradh formation is found in Amal East. Reservoir quality is similar to the Haradh in Amal West, but the oil is much heavier and more viscous. Maximum oil column length is $270 \mathrm{~m}$ on the crest and the Oil Water Contact (OWC) is about $90 \mathrm{~m}$ deeper than in Amal East.

The Amal West field is a continuous steam flood development with reserves of $28.2 \mathrm{MMm}^{3}$ oil by a progressive development through the drilling of a total of 400 injection, production temperature observation and aquifer pump-off wells [44]. Before steam injection can start, the reservoir needs to be depressurized from the current $8000 \mathrm{kPa}$ to around 2000 to $3000 \mathrm{kPa}$ and a period of cold production will therefore precede the steam injection.

Amal East reservoir quality is similar to Amal West, but the oil is much heavier and more viscous $(4,000-20,000$ cp). The Amal East field will start its development with a Cyclic Steam Soak (CSS) through 24 wells. This will develop an initial 1.3 $\mathrm{MMm}^{3}$ of new oil. This CCS may thereafter be followed by a steam drive development of CSS. The Base case production profile for 6000 tpsd and 18000 
tpsd steam injection rate cases are represented graphically in Figures 4-6 for different scenarios [45].

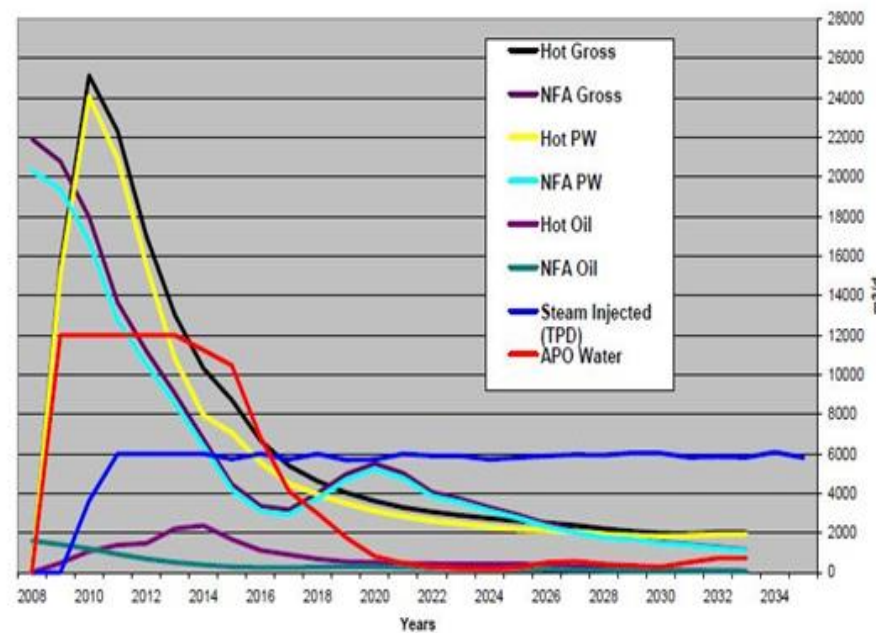

Figure 4: 6,000 TPSD Production and Steam Injection Forecast for Single Tranche

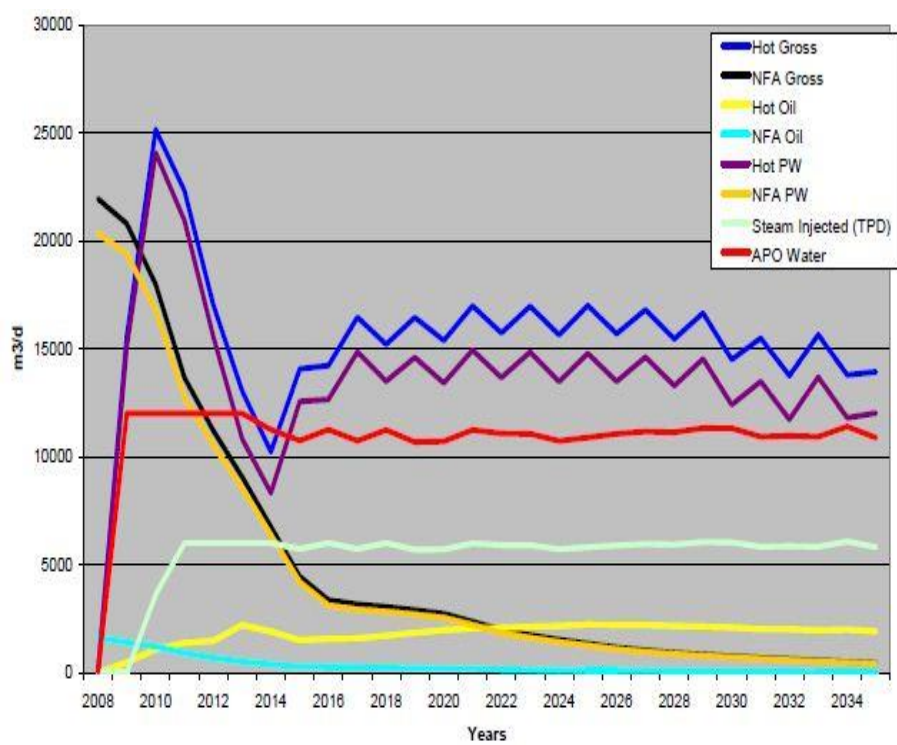

Figure 5: 6,000 TPSD Production and Steam Injection Forecast for Multiple Tranche

From Figures 4 to 6, the gross forecast already is a high case forecast as it assumes all wells to be successful, no well downtime, no delay in drilling or facility installation, fully optimized and fault free operations. Also, as the wells are lift capacity constrained, there are no requirement to add any further contingency on the Base case peak production rate. High case peak thermal gross production will be for stream generation.

Reservoir pressure and beam pump intake pressure is considered to be 20 Bar. The temperature profile of thermal gross production is shown in Figure 7. The temperature data provided is temperature at pump intake. During later part of the field life (2020-2030), enthalpy of the injected steam will equalize to the gross production enthalpy and the gross production will have the peak enthalpy. This corresponds to a maximum production of approximately $15000 \mathrm{~m} 3 / \mathrm{d}$ with temperature of $210^{\circ} \mathrm{C}$ (pump intake temperature). The oil viscosity correlation and the production profile for Amal East are shown in Figures 8 and 9 respectively [46].

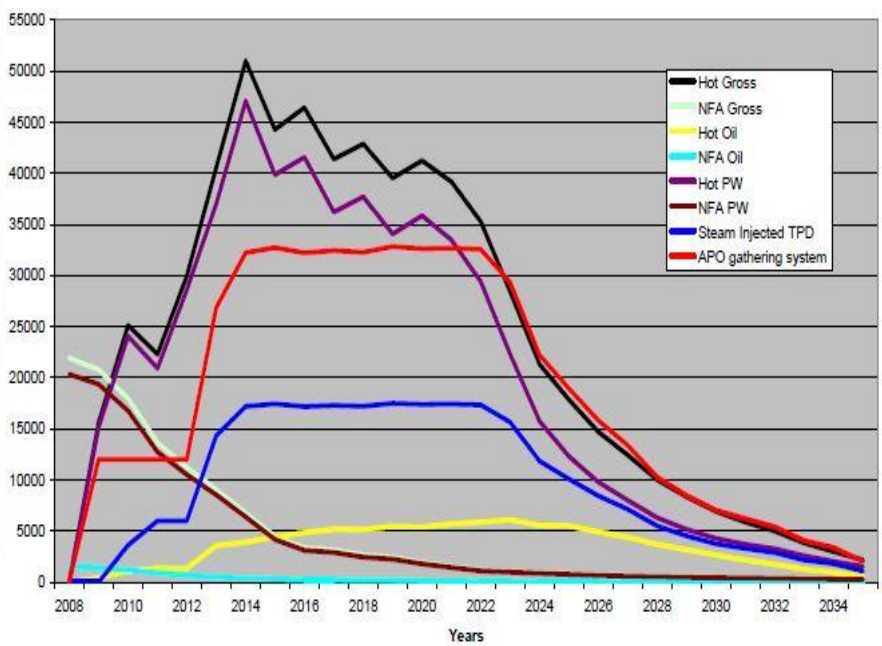

Figure 6: 18,000 TPSD Production and Steam Injection Forecast for Multiple Tranche

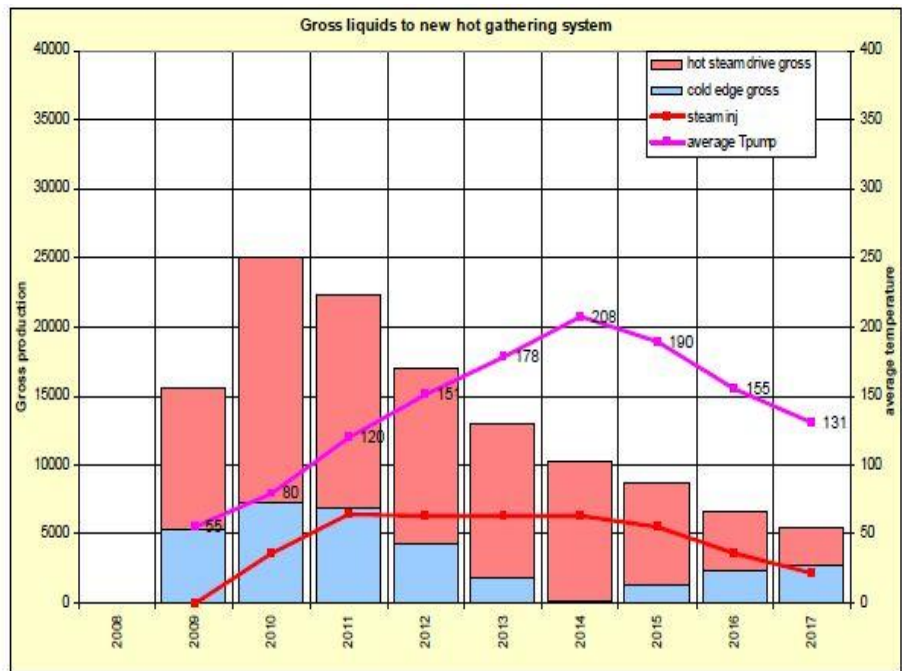

Figure 7: 6,000 TPSD Gross Production Temperature Profile

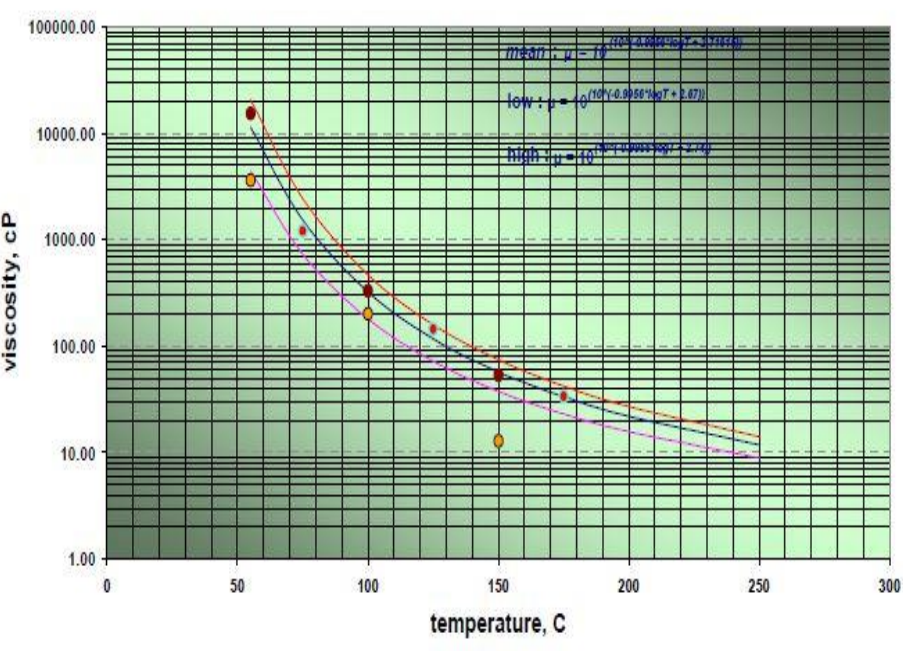

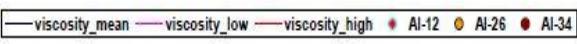

Figure 8: Oil Viscosity Correlation for Amal East 


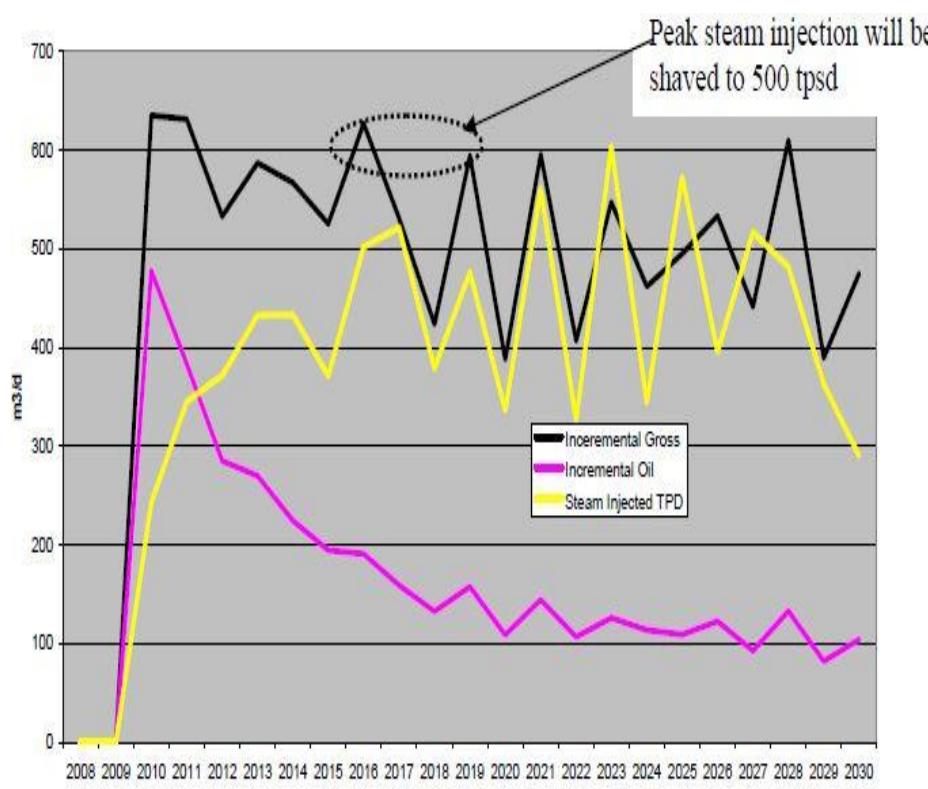

Years

Figure 9: Amal East Production and Steam Injection Forecast

\section{Enhanced Oil Recovery (EOR) Technique in Oman Oil and Gas Sector}

The Petroleum Development Company of Oman (PDO) is the leading exploration and production company in the Sultanate of Oman. It delivers the majority of the country's crude oil production and natural gas supply. PDO operates in a concession area of about $90,000 \mathrm{~km}^{2}$ (one third of Oman's geographical area). PDO remains committed in seeking new and green technologies for energy generation, to reduce its dependence on fuel gas to generate electrical power for business needs [41].

On the other hand, GlassPoint is developing and operating many of the world's largest industrial solar projects by delivering the lowest-cost solar energy to power industrial processes. Glass Point has a strong partnership with energy leaders and strategic investors including Royal Dutch Shell, PDO, Aera Energy, and the State General Reserve Fund of Oman, the country's largest sovereign wealth fund [42].

In order to get oil out of the ground, the reservoir's pressure must be above the bubble point. The bubble point is the first droplet of gas which comes out of the solution of the specific reservoir's pressure. After period of time the reservoir pressure decreases and gets below bubble point which makes it difficult to be extracted, hence EOR is used.

EOR is the process of increasing the amount of oil that can be recovered from an oil reservoir, usually by injecting a substance into an existing oil well to increase pressure and reduce the viscosity of the oil. EOR is a method of recovering oil, in largest scale efficiently. More amount of oil will be recovered from the reservoirs, by this method. There are different types of techniques for enhanced oil recovery. The commonly used three types are as follows [45]:
-Steam injection (recovery by thermal method): Here, the steam is injected at high pressure into the oilfield. The steam heats the oil to make it thinner and thus flow better. Furthermore, it helps to push the oil to wells where it can be drawn to the surface.

-Injection of gas mixes (recovery by gas injection): A cocktail of gases is injected into the oilfield which is mixed with oil and helps it to flow to the well.

-Injection of a mixture of chemicals and water (recovery by chemical injection): Chemicals are mixed with water to make it thicker before it is injected into the oilfield to drive the oil out of the rock.

The largest solar energy project in Oman in used for thermal enhanced oil recovery and is operated by Glass Point for PDO. The project produces 11 tons per hour of highpressure steam that is used to extract 33 thousand barrels of oil and powered by $7 \mathrm{MW}$ solar arrays. The technological developments mean we could be in a verge of a future, where some of the biggest solar projects in the world operate within the oil field.

\section{The Miraah Project}

PDO with Glass Point Company are working together on a project called (Miraah). This project produces 6,000 tons of solar steam each day by using concentrated sunlight. The generated steam directly feed PDO's Amal oilfield in Southern Oman. The generated steam is used in thermal EOR to lead the industrial sector toward a cleaner, lowercarbon future [46]. When this project is completed, it will save 5.6 trillion British Thermal Units (BTUs) of natural gas each year. The purpose of Miraah project is to produce steam by using solar instead of burning gas, which will reduce carbon dioxide $\left(\mathrm{CO}_{2}\right)$ emissions by more than 300,000 tons every year. The location of the project is shown in Figure 10 [47].

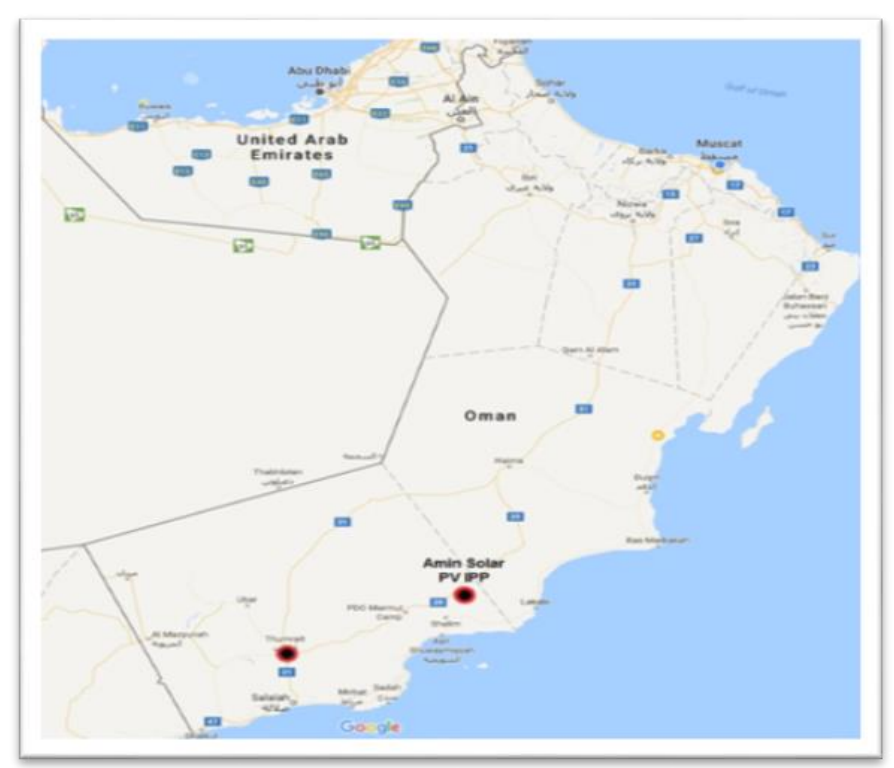

Figure 10: Location of Amin solar PV project 


\section{Solar Steam Generation Concept in Oman}

Solar thermal EOR, is a generic term for techniques for increasing the amount of oil that can be extracted from an oil field. While existing production methods generally recover only $30 \%$ of the oil, EOR techniques facilitate ways to increase this amount by $10 \%$. As mention earlier, the main players of the Miraah project in Oman, are the biggest oil and gas producer (PDO) teaming up with Glass Point, with the following major objectives of; enhanced oil production with solar energy; reduction of carbon emissions and cost. Thermal enhanced oil recovery is the leading method of producing heavy oil. In thermal EOR, high pressure steam is injected into the reservoir making the oil easy to pump to the surface by boosting the productivity up to $300 \%$. Producing steam for EOR requires burning huge amount of natural gas which is considered to be the valuable resource that is in short supply in many of the world's oil producing region. Using the sun to generate steam for EOR, significantly reduces the amount of natural gas burnt. Glass point solar steam generators are designed specifically for oil and gas industries. Mirrors inside the glass house track the sun focusing its heat into a pipe that is carrying water converting it into steam. The glass house protects the mirrors from sand and dust which is common in oil producing regions. The deployed solar EOR scheme in heavy oil fields encourages reduction in natural gas consumption, reduction in carbon dioxide emissions and increase local job creations.

Potential solar energy in Oman has the ability to generate 20, 000 tons/day wet steam of pressure 40 bars, at $50{ }^{\circ} \mathrm{C}$. The Amal steam project in Oman is shown in Figure 11 [44], with intent of replacing the traditional boiler steam technology earlier discussed. The following are the components of the solar system; flat plate collectors, vacuum

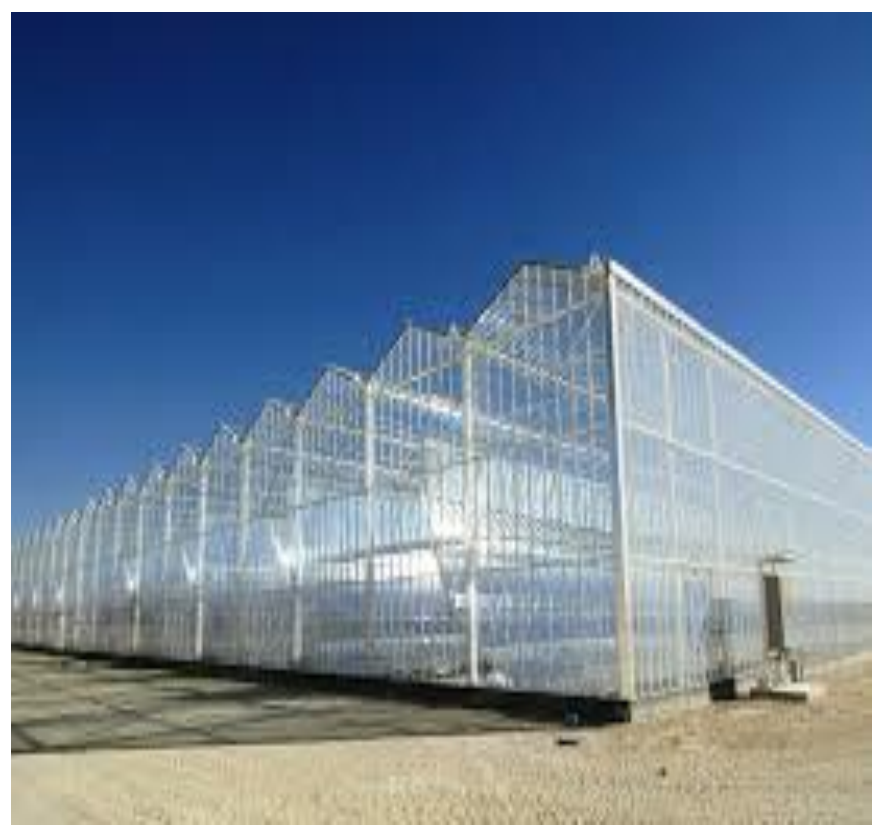

Figure 11: Amal steam project

-tube collectors, dishes, fresnel, parabolic troughs, and the power towers. The main design parameters are: power, temperature, efficiency, and costs. Figure 12 shows various thermal collectors and the two-tracking system of solar panel used for this work.

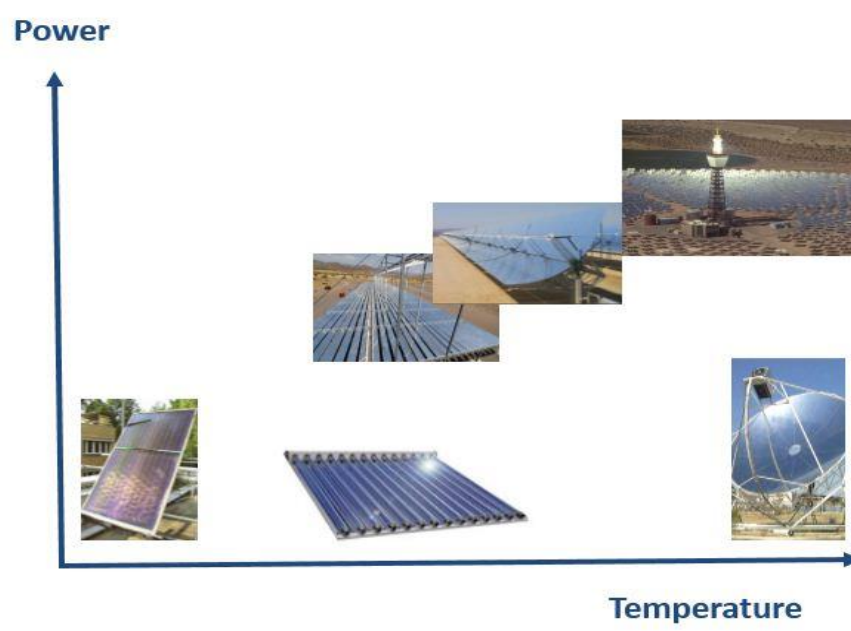

(a) Various designs

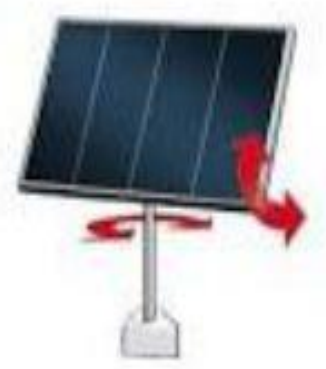

(b) Two tracking

Figure 12: Solar collector types

\section{The Solar Steam Generator Model System}

Each of the solar collectors is a trough-shaped mirror (with a parabolic cross-section) that tracks the sun and focuses the light on to a tube containing heat transfer fluid which is normally some kind of oil. The hot oil passes through a solar super heater and steam generator where the heat boils water and creates superheated steam. The steam drives the turbine, the turbine drives the generator and that feeds electricity into the electricity transmission grid.

Steam that comes out of the turbine is still quite hot. It is fed through a condenser where it is cooled down by cooling water from a cooling tower. The cooled water is fed back into the steam generator and solar super heater to create superheated steam again, and this is fed back into the turbine to generate more electricity. Part of the generated hot steam is channeled into the oil wells for EOR process. So, the solar steam generator serves the dual purpose of electricity generation to the community, where the host field is located and also for EOR in the oil wells. Figure 13 shows the general concept of the solar steam generator [48], while Figures 14 and 15 show the steam generator strategy used for the Miraah project. The Amal solar steam generator pilot with 50 tons of 100 bar $80 \%$ steam per day production are shown in Figures 16 and 17 respectively. 


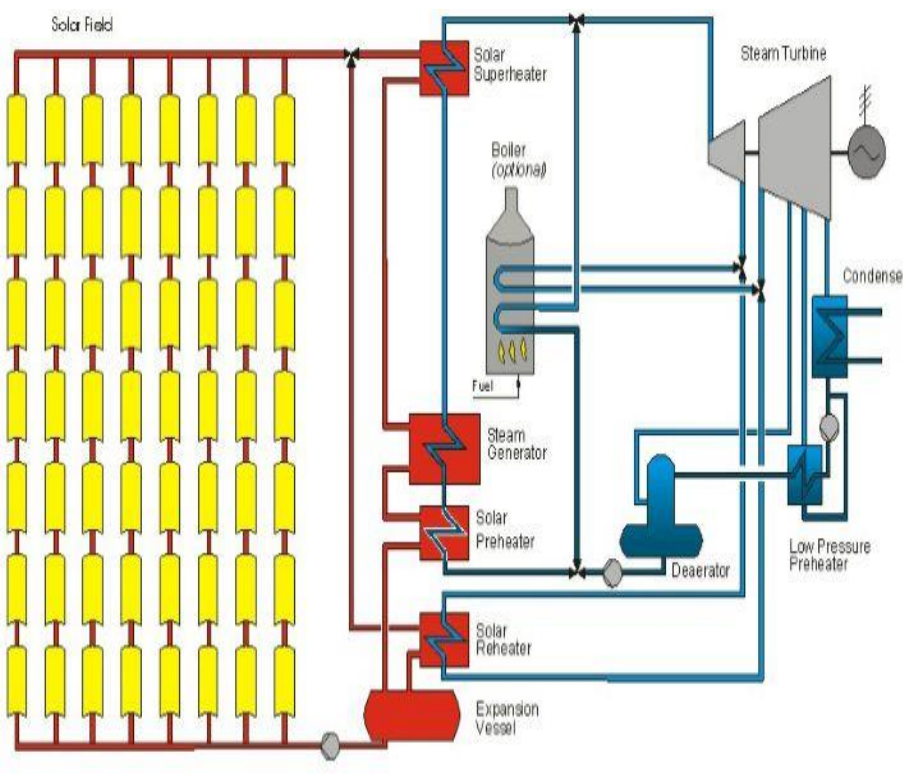

Figure 13: General concept of solar steam generation

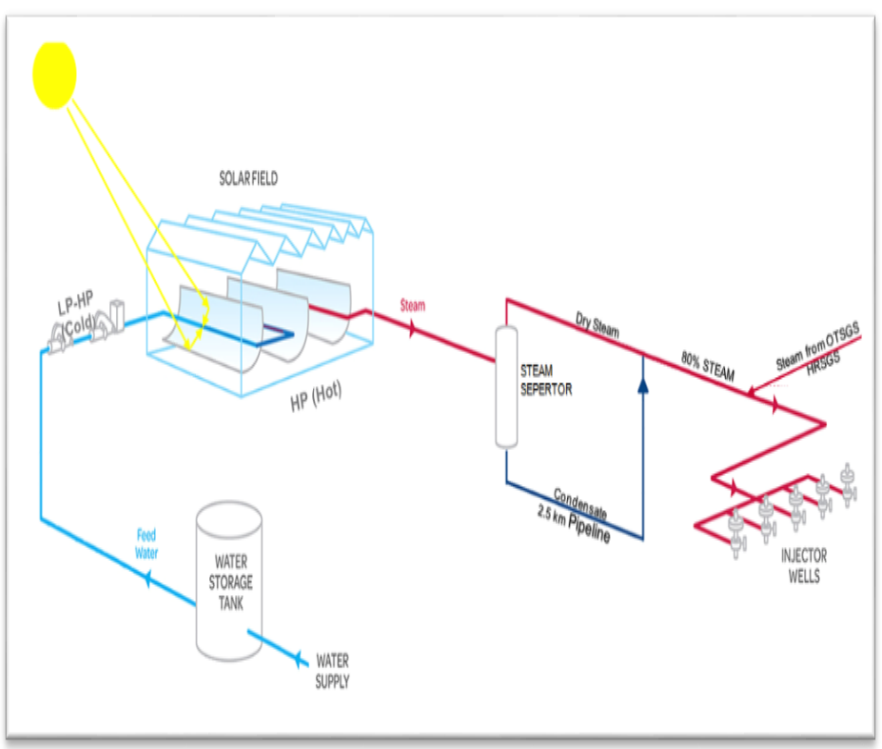

Figure 14: Process of Miraah Project

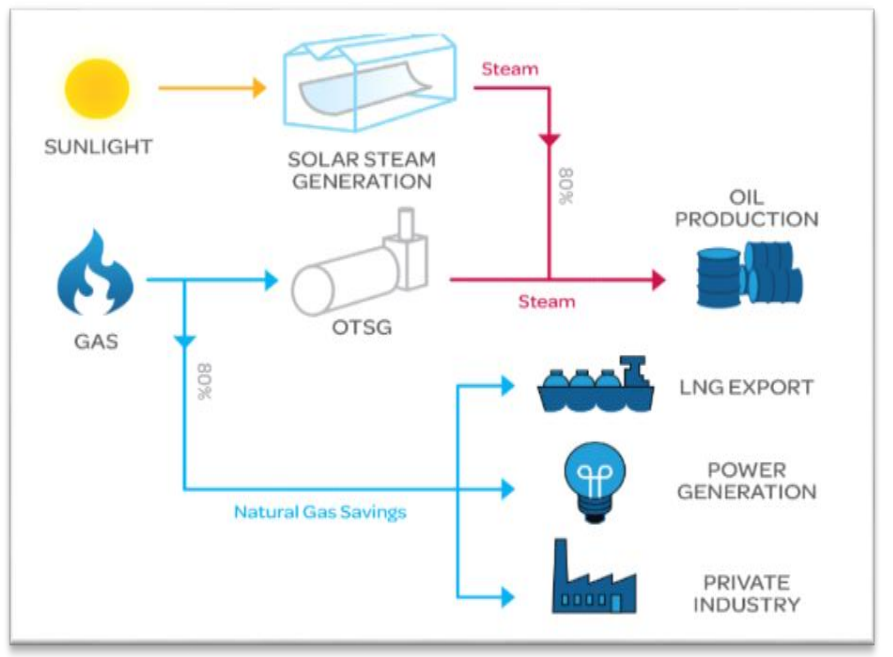

Figure 15: Gas savings from Miraah project

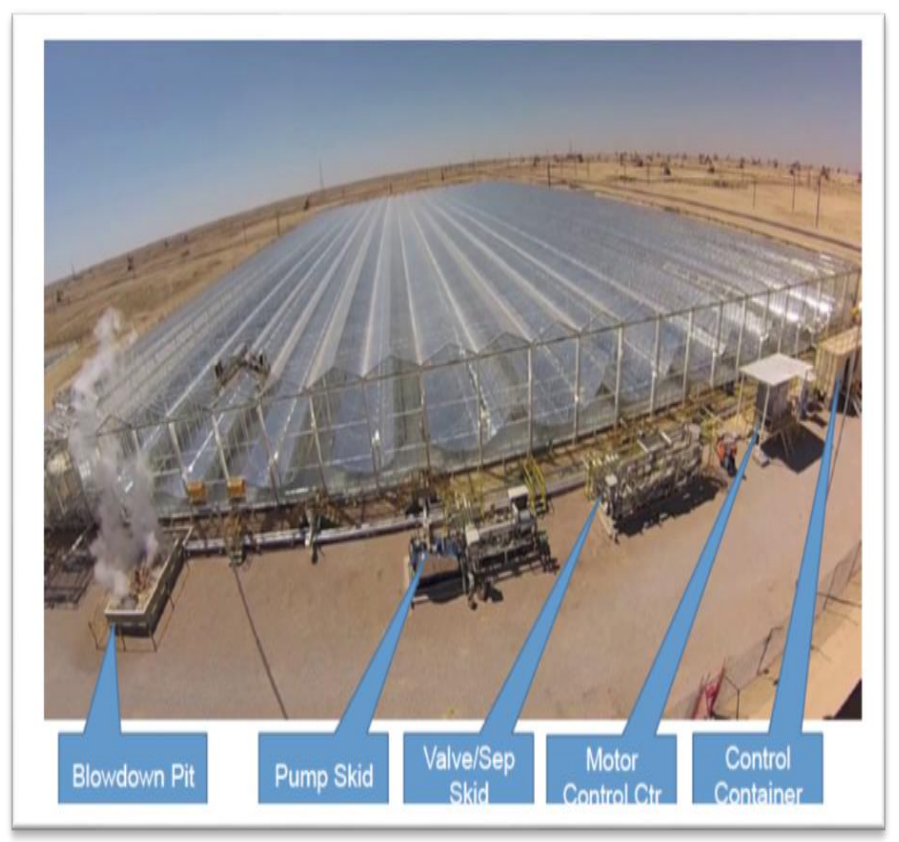

Figure 16: Detailed layout of the Miraah structure in Amal

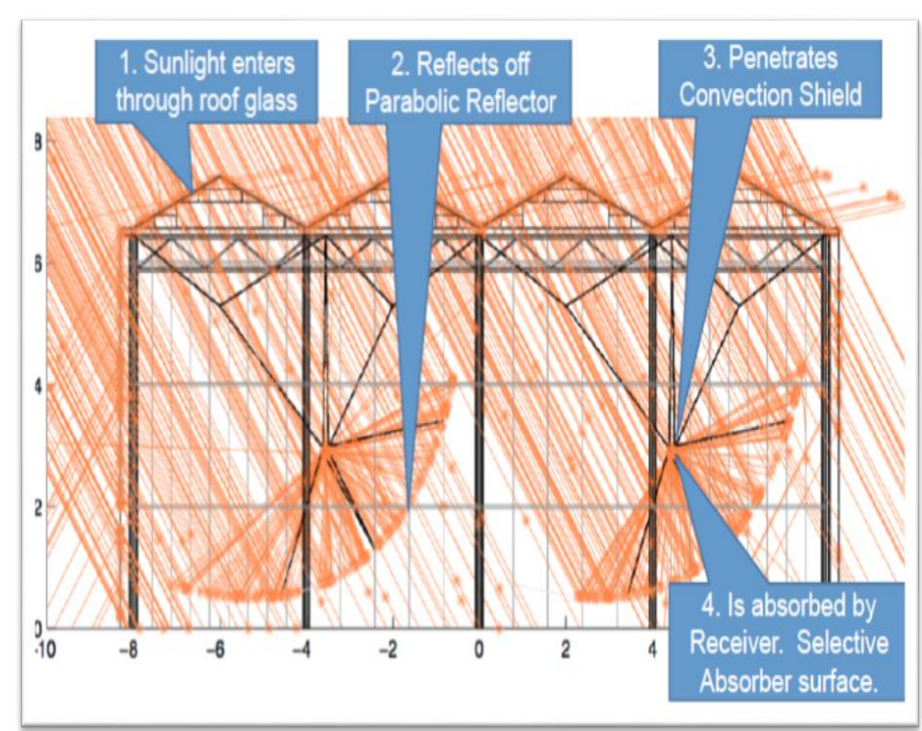

Figure 17: Miraah Project Methodology

Based on Figures 13 to 17 , by using curved mirrors to focus sunlight onto a pipe filled with water, steam is created by the concentrated sunlight, as a result of the use of the Concentrated Solar Power (CSP) which boils the water filled in the pipe; steam is directly fed to the oilfield. The quality of the steam produced by solar is the same as the steam produced by natural gas in terms of pressure and temperature. The mirror is mounted on a steel or aluminum structure. In most cases a hydraulic drive is used for tracking the collector structure. A Heat Transfer Fluid (HTF) is circulated through the absorber tubes and heated up and then injected to the wells. At night or low solar irradiation, the conventional steam generators are used to generate the thermal energy [48]. 


\section{Design Calculations and Expected Outcome}

The construction of Amal project has three phases and the expected production of each phase is different. The total production of the three phases is 6000 tons of steam per day. Phase one is almost completed and will produce $10 \%$ of the total production, phase two is still under construction and will produce $30 \%$ of the total production and the construction of phase three which started in 2018 will produce $60 \%$ of the total production. Phase one consists of four blocks and each block has different loops. Block one and three has five loops each, whereas block two and four has four loops. Each loop is equal to eight rows and each row has three mirrors, so the total number of mirrors in phase one is 432 mirrors. The system when built out will have a total of two glass houses per module in phase one. Solar thermal energy is trapped in an enclosed glass house, in which parabolic shaped mirrors are installed. The sun light impinging on the parabolic shaped mirror is concentrated on a special steel pipe of three inches diameter, in which water is flowing. The special steel pipe is positioned at the focal point of the parabolic shaped mirror. The heat energy concentrated on the special steel tube is used to heat the water to make steam. The steam is then transported to PDO station to be injected to the oil reservoir. The glass house protects the mirrors from dust, which is very much required to achieve the maximum efficiency. In contrast, the mirrors can be installed in open atmosphere, but the efficiency will be drastically reduced due to continuous dust that will be formed in the desert environment [43, 44]. To clean the roof top of the glass house, high speed roof washers are installed, which wash the glass house roof top periodically and this can be done by operator.

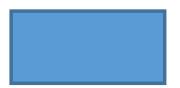

1

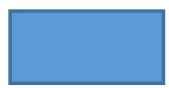

2

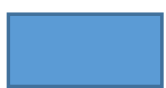

3

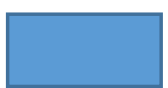

4
Figure 18: Mirror Segments

Each mirror segment is of length 12.5 meters (Figure 18) and the arrangement is shown in Figure 19 and 20 respectively. From Figure 20, phase 1 has capacity of 660 tons per day with four glasses, while phase 2 has capacity of 1320 tons per day with 8 glasses. The gap between two mirrors is filled up by gap mirrors of length 2.5 meters. All the 4 segments together make one full mirror of 60 meters long. The mirror's position is controlled by a small AllenBradley controller that calculates the sun's position using a Solar Positioning Algorithm (SPA) and moves the mirrors into position using the feedback from inclinometers mounted on the mirrors.

Each Allen-Bradley controller (Micro-850 PLC) will position four mirrors that are 60 meters long. Each mirror has four stepper motors connected to them to drive them to the correct angular position. Each motor has an inclinometer for feedback to position the mirror. Hence, for a Mirror there would be four stepper motors and four inclinometers. Four such mirrors are controlled by 1 Micro-850 PLC. There will be a total of 108 Allen-Bradley controllers per module, 54 per glasshouse. When the system is fully built out there will be a total of 108 Allen-Bradley controllers controlling all the glass house mirrors in the system.

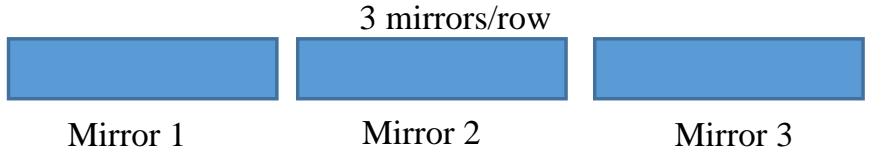

Figure 19: Mirror arrangements

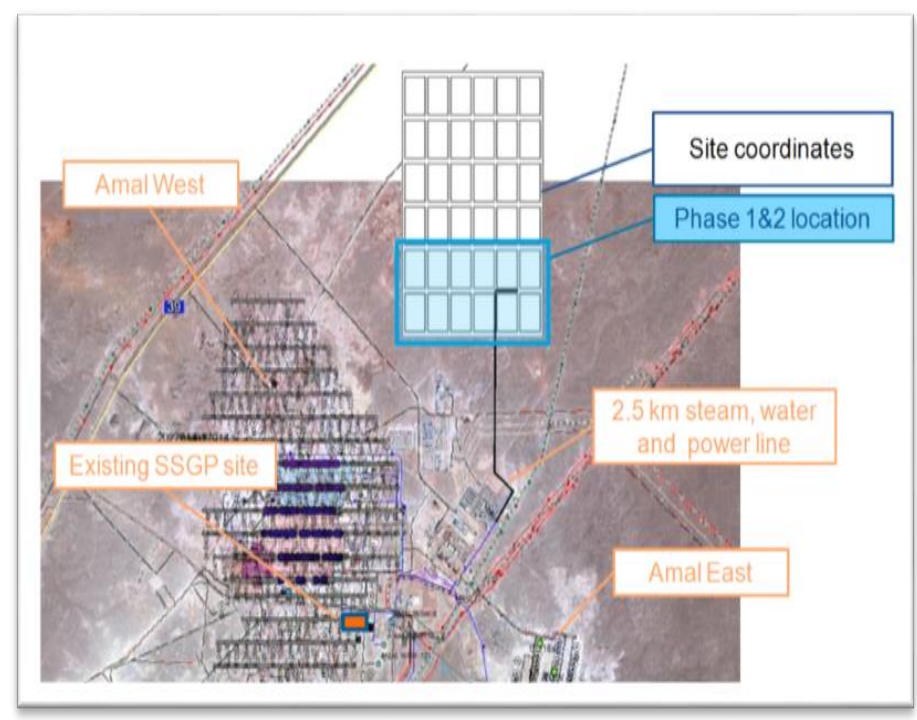

Figure 20: Amal Solar (Mirrah) phases 1 and 2

Eight such rows constitute a production loop, which would produce approximately 30 tons of steam per day. As per design calculations, to produce 6000 tons of steam per day, $1 \mathrm{GW}$ of electrical energy is consumed or $166 \mathrm{~kW}$ (approximately) electrical energy is required to make 1 ton of steam. Figure 21 shows the mirror inclination in the steam generation system.

The glass in parabolic mirror runs east-west. To convert from solar Azimuth and Zenith, this equation can be used to get the south facing elevation angle [49]:

$e l=\tan ^{-1}\left(\frac{1}{\tan (z) * \cos (A-\pi)}\right)$

The mirror has an absolute inclinometer, whose angle, $i$, is positive when the mirror is pointing south, as shown above, and negative when the mirror points toward the north. To calculate position error, it is useful to convert the south facing elevation angle into a south facing zenith angle, which is the desired control parameter, $i_{-}$des:

i_des $=\frac{\pi}{2}-\tan ^{-1}\left(\frac{1}{\tan (z) * \cos (A-\pi)}\right)$ 


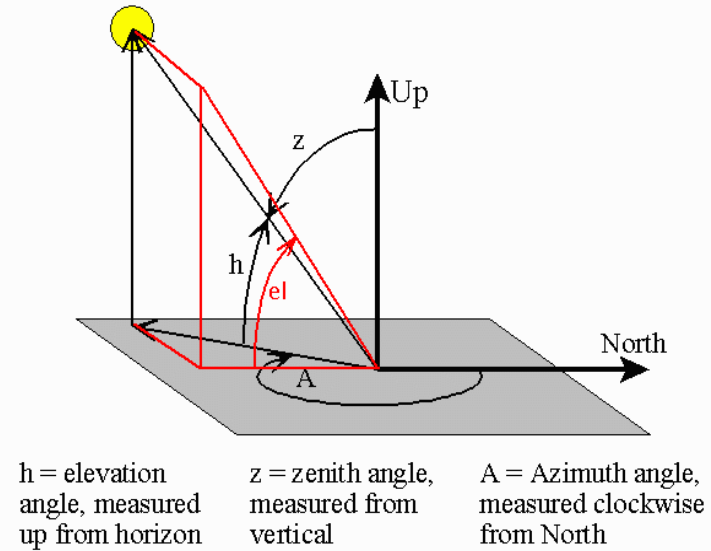

(a)

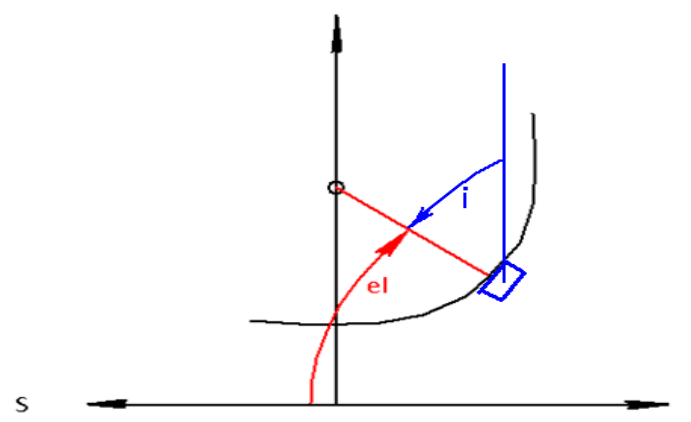

(b)

Figure 21: Mirror Inclination

For control, the angle error can then be calculated as follows:

$e=i_{\text {des }}-i-$ Tracking Offset Angle from Master Controller

The comparison between electricity and steam supply for EOR process for one well daily fuel use is shown in Figure 22. From Figure 22, the use of steam for EOR is more than the use of electricity. Therefore, if the steam generator model presented in this work for the Miraah project could generate such amount of steam as primary energy source for EOR, then a lot of cost would be saved with little or no pollution to the environment.

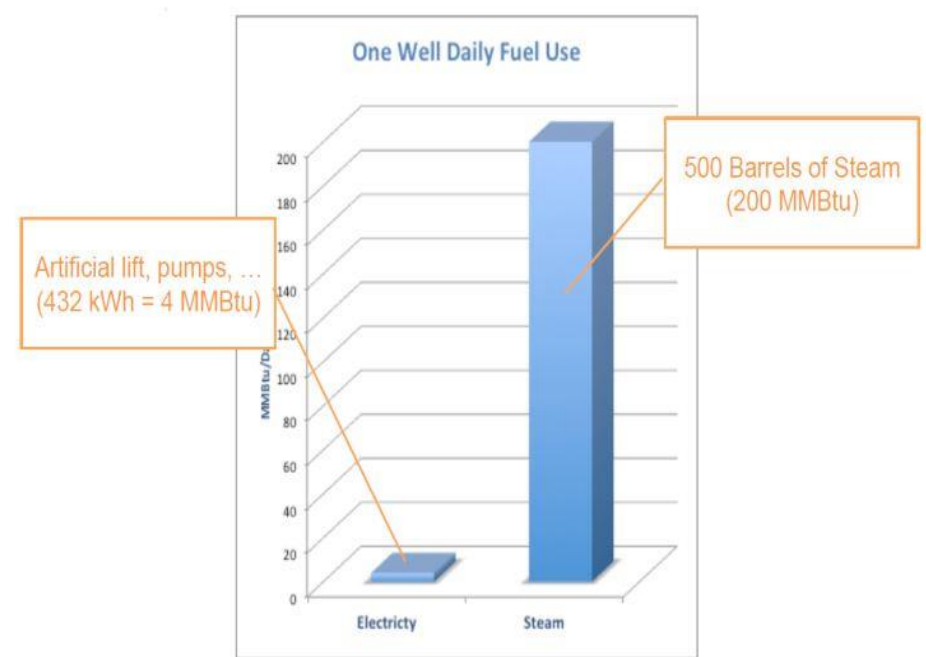

Figure 22: Energy usage for Enhanced Oil Recovery

\section{Benefits of employing Concentrated Solar Power at Mirrah Projects}

Some of the benefits in employing the Consecrated Solar Power system (CSP) in this study are:

- Save of natural gas for power generation or LNG export

- Less environmental impact

- Steam flood Recovery Rate and Ultimate Recovery (RRUR), not affected.

- Provide one third of Amal's EOR steam from solar

- At 1GigaWatt thermal (GWth), it will be the world's largest solar field

- Project creates direct economic value to Oman

- PDO pays slightly more for steam.

- Gas not burned, can be exported, or used to create jobs

$\circ \quad$ Future projects will be price competitive with natural gas

- Create a new high-technology industry in Oman

\section{Challenges of the Concentrated Solar Power (CSP)}

Some of the challenges in employing the CSP system in this study are:

- Water consumption: Large amount of water is required for CSP plants. For current CSP systems, the water requirement is estimated between 3 and $3.5 \mathrm{~m}^{3} / \mathrm{kWh}, 95 \%$ of which is attributed to cooling tower and $5 \%$ is consumed for mirror cleaning.

- Dry cooling: Currently, most commercialized CSP plants are integrated with conventional steam Rankine cycle for power generation. Wet cooling can provide higher conversion efficiency than dry cooling because the exhaust steam with wet cooling can be cooled faster to a lower temperature.

- Dust cleaning: Dust accumulation on mirrors or on solar collectors is a major problem in CSP plants. The reflectance of the mirrors or the transmittance of solar absorbers reduce due to the dust accumulation and so as the efficiency of the CSP system. The CSP plants in the study are mainly in the desert regions, with the possibility of very high dust accumulation.

- Location: Most of the solar energy falls on remote areas and would therefore require existing power transmission network to be useful to their serving communities.

- $\quad$ Thermal Energy Storage (TES): Daily and seasonal variations in irradiance, exacerbated by variations owing to weather, introduce the need for storage system for continuous operation. 


\section{Some Opportunities offered by the Miraah Solar Farm Project}

PDO has the opportunity of selling the energy generated from the solar farm. The aim is to save more gas, save the environment from $\mathrm{CO}_{2}$ emissions and to make the grid more stable. The Japanese company (Marubeni United) will buy electricity for its operations in the operation areas from Amin oilfield, in southern concession area with tariffs that are among the lowest tariffs in the world [50]. The value of the low tariff showed the great potential to produce solar energy at commercially attractive prices by the Sultanate.

Also, there would be revenue generation and effective management of generated energy from the solar farm. The main aim of solar farm project set up by PDO is to reduce cost and to protect the environment from gas emissions. The firm will operate with more effective management system, which will run the grid project with less faults and issues. In terms of working efficiently, the grid most have a list of requirements such as:

\section{- Decentralized software platform}

- Dynamic energy management system.

- Secure energy via apps.

- Stability of the generated power.

The fear of oil and gas price variation and global warming are the main issues behind the idea to produce green electricity from renewable sources. A good example for revenue generation for PDO from solar energy would be the greenhouse emission project. The PDO solar farm could be used too as a sustainable source of electricity from renewable energy to save a big amount of money that was spent in the production line and the same time gradually mitigate the overdependence on oil and gas for power generation in the Sultanate. Hence, there are possibilities of smart grid implementation in Oman via this channel. New job opportunities would be created for the citizenry of the Sultanate. In addition, this system could help the electrical side demand management or integration. By doing this, there will be effective management of peak hours to make the power system more efficient.

\section{Conclusion and Recommendations}

According to statistics, Oman oil and gas resources will be consumed fully within the span of 30 years. However, with increasing population, consumption of energy is on the rise. Recently, the government of the Sultanate of Oman is encouraging the use of solar energy in order to help fill potential energy deficits. Generating steam using solar energy has overcome the challenges of steam been produced from burning of natural gas. The most common challenge is that the steam production facilities using natural gas burnt facilities are expensive and the cost of natural gas required to generate steam is considerably high. In this paper, the following key points are noteworthy;
- The state-of-the-art and prospects of solar energy in the oil and gas industries, with case study of Amal and Amin oil fields in Oman, known as the Miraah solar farm were presented

- This solar farm project is a joint venture operated by the major key player of the oil and gas industry of Oman, known as Petroleum Development Company of Oman (PDO) and their partner Glasspoint Company

- The renewable energy steam generated system is of paramount importance for the oil and gas industries, as it will serve dual function of ensuring optimal drilling of the oil in a cost-effective way and offer friendly environmental solutions, by reducing pollutions

- Furthermore, the solar power farm scheme could serve as a source of power to the immediate community in particular and the country in general

- Creation of jobs and revenue when the solar steam generated system is operated as an integral of smart grid network

- Project creates direct economic value to Oman

- Creating environment for future projects that will be price competitive with natural gas

- Creating a new high-technology industry in Oman would be achieved.

- Also, employing solar power to generate steam in the case of the Amal oil fields reduces the total operating cost and protect the environment from carbon emissions.

- Thus, it is recommended that the Omani government and oil and gas industries in the region should utilize the natural resources of renewable energy (solar) fully and use them to develop the country by providing the growing energy needs.

\section{Acknowledgements}

The authors would like to acknowledge staffers of Petroleum Development Company Oman and Glasspoint for their support in this study.

\section{References}

[1] Authority for electricity regulation in Oman, study on renewable resources Oman (May, 2008): Final Report, p.14.

[2] Kazem A. H. (2011) Renewable energy in Oman: status and future prospects, Renewable and Sustainable Energy Reviews, 15, 3465-3469.

[3] Dipippo R (2012) Geothermal power plants: principles, applications, case studies and environmental impact, 3rd edn. Butterworth-Heinemann, USA. 
[4] Dipippo R. (2004) Second Law assessment of binary plants generating power from low temperature geothermal fluids. Geothermic 33(5):565-586.

[5] Environmental Protection Agency (2008) Energy and environmental analysis. Technology characterization: reciprocating engines. Combined heat and power partnership program.

[6] Oman Electricity and Transmission Company OETC (2016).

[7] Puja M (2016) Solar energy: 10 major applications of solar energy-explained.

[8] Jiang,Q (2010) 2010-2015 China Solar Energy Industry Investment Analysis and Forecast Report.

[9] Manning,Paddy(2010) With green power comes great responsibility http://www.smh.com.au/business/withgreen-power-comes-greatresponsibility20091009gqvt.html (accessed on 13 JAN 2010).

[10] Ronal L\&Ronald E, W (1996) Implementation of solar thermal energy.

[11]Xu, W (2009) China Solar Building Application Development Study 2009.

[12] Hernández-Moro J, Martínez-Duart JM (2013) Analytical model for solar PV and CSP electricity costs: present LCOE values and their future evolution. Renew Sustain Energy Rev 20:119-132.

[13] Skoplaki E, Palyvos JA (2009) On the temperature dependence of photovoltaic module electrical performance: a review of efficiency/power correlations. Sol Energy 83(5):614-624.

[14] Viebahn P, Lechon Y, Trieb F (2011) The potential role of concentrated solar power (CSP) in Africa and Europe: a dynamic assessment of technology development, cost development and life cycle inventories until 2050. Energy Policy 39(8):4420-4430.

[15] Montes MJ, Rovira A, Muñoz M, Martínez-Val JM (2011) Performance analysis of an integrated solar combined cycle using Direct Steam Generation in parabolic trough collectors. Appl Energy 88(9):32283238 .

[16] Ministry of Energy and Power Division (2017), Government of Pakistan: Alternative Energy Development Board.

[17] Jingcheng L. (2010) Application of Solar Energy, Thesis, Saimaa University of Applied Science, Lappeenranta.

[18] Hassanien RHE (2016) Advanced Application of Solar Energy in Agricultural Greenhouses, Renewable and Sustainable Energy Reviews, 54, 989-1001.

[19]Zhang Y., Sivakumar M., Yang S., Enever K., Ramezanianpour M., (2018) Application of Solar Energy in Water Treatment Process: A review, Desalination, 428, 116-145.
[20]Rizzo G., (2010) Automotive Applications of Solar Energy, IFAC Proceedings, 43(7), 174-185.

[21] Georgy Zerkaloy (2015), Steam injection for Enhanced oil Recovery.

[22] Kazeem Akintayo Lawal, (2011), Alternating injection of steam and $\mathrm{CO}_{2}$ for thermal Recovery of heavy oil", PhD Thesis, pp-4

[23] Okedu K. E and Uhunmwangho R., (2015), Renewable energy in Nigeria: The challenges and opportunities in mountainous and riverine regions, International Journal of Renewable Energy Research, IJRER, 5(1), 222-229.

[24] Ministry of National Economy. Statistical Yearbook. November; 2010.

[25] Ministry of Oil \& Gas, letter dated 13 February 2008. Ref. 478.

[26] Oman Power and Water Procurement. Annual Report; 2006.

[27] Oman Power and Water procurement. Seven Years Statement; 2007-2013.

[28] Al-Badi AH, Malik A, Gastle A. (2009) Assessment of renewable energy resources potential in Oman and identification of barrier to their significant utilization. Renewable and Sustainable Energy Reviews 13: 2734-9.

[29] Guenther Glatz (2013) A Primer on Enhanced Oil Recovery, Physics 240, Stanford University, Fall.

[30] Nugroho W.A., A. Z. Abidin, and T. Puspasari, (2012), Polymers for Enhanced Oil Recovery Technology, Procedia Chem. 4, pp 11.

[31] Salehi A., (2013) CO2 Injection for Enhanced oil Recovery, Physics 240, Stanford University, Fall.

[32] Soteris A. Kalogirou, (2011), Concentrated Solar Power Plant for Electricity and Desalinated Water, World Renewable Energy Congress, Sweden.

[33]AER (Authority for Electricity Regulation) (2008), Study on Renewable Energy Resources in Oman, AER, Muscat.

[34] IEA (International Energy Agency) (2013), "World Energy Outlook 2013”.

[35] IEA (International Energy Agency) (2012), “World Energy Outlook 2012”.

[36] The Oman Power and Water Procurement Company, 2018.

[37] The Oman Power and Water Procurement Company, 2018.

[38] Booz \& Co. (2010b), "The Future of IPPs in the GCC: New Policies for a Growing and Evolving Electricity Market", strategy and pwc.com/global/home/what-wethink/reports-white-papers/article-display/future-ippspolicies-growingevolving.

[39] Okedu K. E, and Al-Hashmi M., (2018) “Assessment of the Cost of various Renewable Energy Systems to 
Provide Power for a Small Community: Case of Bukha, Oman", International Journal of Smart Grid, vol.2, no. 3, pp. 172-182, 2018.

[40] Okedu K. E, and AL Salmani Z. Waleed, (2019) "Smart Grid Technologies in Gulf Cooperation Council Countries: Challenges and Opportunities", International Journal of Smart Grid, vol.3, no. 2, pp. 92-102.

[41] Petroleum Development Company of Oman, 2016.

[42] Petroleum Development Company of Oman, 2017.

[43] Glass Point Engineering, 2016.

[44] Glass Point Engineering, 2017.
[45]PDO.co.om. (2019). PDO. [online] Available at: https://www.pdo.co.om/en/Pages/Home.aspx [Accessed 11 May 2019].

[46] Glasspoint Engineering (2019).

[47] Google Map, 2018.

[48] Bierman, B., Treynor, C., O’Donnell, J., Lawrence, M., Chandra, M., Farver, A., Von Behrens, P. and Lindsay, W., (2014) "Performance of an Enclosed Trough EOR System in South Oman", Energy Procedia, 49, pp.12691278.

[49] Rai G.D., (2013) Non-conventional Energy Sources, Khanna Publishers, Fifth Edition.

[50] Zindler, E. (2019) www.bcse.org, 13 Feb. 